\title{
Review on Genetic, Environment and Their Interaction (G x E) for Stability of Coffee Quality
}

\author{
Dula Geneti \\ Ethiopian Institute of Agricultural Research, Jimma Agricultural Research Center, \\ Jimma, Ethiopia; p.o.box 192
}

\begin{abstract}
Coffee (Coffea arabica L.) is a highly valuable export commodity in the world. More than 50 developing countries, 25 of them in Africa. The labor intensive tree crop also provides much employment in rural areas. However, international market has always been fluctuating affected mainly by Genetic, environment and its' interaction. Diversity of coffee quality due to $\mathrm{G} x \mathrm{E}$, result from influences on the biochemical components of the coffee bean accumulated during seed development. Assessment of coffee quality is usually focused on factors that influence utilization of the final product with consumer preferences being assessed in three primary ways: physical (e.g. bean size), sensorial (cup quality) and chemical analysis. Previous studies on coffee have shown that there is a differential response of quality when grown under different conditions and environments. Nevertheless, further research is important with understanding of coffee metabolism, different genotypes or environment impacts on coffee metabolism and how gene, environment and their interaction affects coffee quality.
\end{abstract}

DOI: $10.7176 / \mathrm{JBAH} / 9-21-04$

Publication date: November $30^{\text {th }} 2019$

\section{Introduction}

Coffee (Coffea arabica L.) belongs to the family Rubiaceae and the genus Coffea (Coste, 1992). The two important commercial species among 124 species in the genus Coffea (Davis et al., 2012) are Arabica coffee and Robusta coffee (Coffea canephora P.), in which the former is the only tetraploid species $(2 n=4 x=44)$, while the latter is diploid $(2 \mathrm{n}=2 \mathrm{x}=22)$ (Gichuru et al., 2008) both cover about 10 million hectares worldwide (Bunn, 2015). Coffee arabica, unlike many other coffee types is considered to be a $95 \%$ self-fertile and only $5 \%$ cross fertile species, meaning it can set fruit from its own pollen (Veddeler et al., 2008). The labor intensive tree crop also provides much employment in rural areas and is the means of livelihood for million of people.

Diversity of coffee quality due to GxE, result from influences on the biochemical components of the coffee bean accumulated during seed development (Joët et al., 2010). For instance, Ethiopia is well-known for its very fine cup quality, unique aroma and flavor across coffee growing areas. Some of the famous coffee types that are acclaimed for having such unique and distinct characteristics include Sidamo, Yirgachefe, Hararge, Ghimbi and Limu (Workafes and Kassu, 2000).

Despite the existence very fine cup quality in coffee population that provides immense opportunities for improvement program for Coffee quality varies in different genotypes of Arabica coffee, which contributes around $70 \%$ of the world coffee production (ICO 2013), is higher quality with lower caffeine and produces a more aromatic brew when compared to Robusta coffee (Ky C. L et al., 2001; Silvarolla et al., 2004).

Environment factors, such as shade and high altitude also have been observed to improve coffee quality (Joët et al., 2010). Numerous studies have been conducted in this field, especially in relation to biochemical constituents such as caffeine, trigonelline, chlorogenic acids (CGAs), sucrose and lipids, considered to influence commercially important sensory traits. The metabolism of these compounds has been studied for decades. However, significant knowledge gaps still exist and more studies are required to more fully define genetic and environmental influences on coffee quality.

Coffee quality results from interaction among many different factors including genotype $(\mathrm{G})$ and environment (E) (Sunarharum et al., 2014). Consumers of high quality coffee may exercise preference for genotype with labeling of species (e.g. arabica) or environment of production (usually country). In this review detailed focus is review on influence of G X E interaction and quality stability in coffee, because of Coffee price in the international market has always been fluctuating affected mainly by overproduction. In this situation, assessment of coffee quality by G X E interaction could provide information on the current situation of coffee quality that are dwindling at an alarming rate in international arabica coffee market and also identifying future research areas to solve production problems with in adequate knowledge of coffee quality.

\section{Discussion}

Coffee is susceptible to aggravating circumstances because of being a biennial crop, in which there is temporal variability in the productivity of plants during different harvests. Thus, review are needed to evaluate the responses of coffee cultivars in different harvests in the coffee-growing regions. Success of a new variety depends to a great extent on its adaptability to a wide range of climatic and soil conditions. Coffee can be cultivated on a wide range 
of soil types, provided these are at least $2 \mathrm{~m}$ deep, free-draining loams with a good water-holding capacity and a $\mathrm{pH}$ of 5-6, fertile and contain at least $2 \%$ organic matter. Among different specious of coffea High-quality, acidic Arabica coffees are mostly produced on soils of volcanic origin. Arabica coffee is grown in altitude ranges between 1400 and $1800 \mathrm{~m}$ above sea level. The optimum mean annual temperature range for Arabica coffee is $18-21^{\circ} \mathrm{C}$. Rainfall requirements depend on their retention properties of the soil, atmospheric humidity and cloud cover, as well as cultivation practices. The optimum annual rainfall range is $1200-1800 \mathrm{~mm}$ for Arabica coffee with a maximum of $2500 \mathrm{~mm}$.

Coffee plants grow and yield better if exposed to alternate cycles of wet and dry seasons. Abundant rainfall throughout the year often results in scattered harvest and low yields. The distribution of sunshine also has a strong influence on flowering, bean expansion and ripening. Shade decreases coffee tree productivity by about $20 \%$, but reduces the alternate bearing pattern. Knowledge of the effects of environment and genotype by environment (G $\mathrm{x} \mathrm{E}$ ) interaction is important to breeders in making decisions regarding the development, evaluation and release of new cultivars. Identifying high yielding and quality coffee genotypes is often time consuming and difficult to achieve due to the perennial nature of the crop, biennial bearing, and the large environmental component of variance for yield and quality (Wamatu et al., 2003).

\subsection{Influence of genotype and environment on coffee quality}

Assessment of coffee quality is usually focused on factors that influence utilization of the final product with consumer preferences being assessed in three primary ways: physical (e.g. bean size), sensorial (cup quality) and chemical analysis (key compounds attributed to quality).

\subsubsection{Physical attributes}

\section{A. Bean size}

Price is related to bean size and small beans of the same variety bring lower prices; however, larger beans do not necessarily taste better; Ideally, roasting should be processed with uniform beans (Wintgens, 2012). When roasting with uneven beans, the smallest tend to burn or over roasted while the largest tend to be under-roasted, which affects both the visual appearance of coffee beans and cup quality (Muschler, 2001). Arabica coffee beans are larger than Robusta coffee beans, ranging between 18-22g and 12-15g per 100 beans, respectively (Wintgens, 2012). Bean size also changes with different environments (Muschler, 2001). As a positive factor, shade increases and unifies bean size by reducing the solar radiance in the coffee canopy and results in a lower air temperature and slowing down of coffee maturation. In addition, as floral initiation is light dependent, fewer flowers developed under lower solar radiance resulting in lower fruit productivity. Both these factors enable more bean filling due to longer assimilation into fewer beans (Muschler, 2001).

Interestingly, even when grown in the same shade environment provided by shade trees, the adaption to shade varies in different genotypes, for example, a relatively greater increase in bean size was found in C. arabica var. Catimor than in C. arabica var. Caturra (29\% and 20\% increase in large bean size, respectively). This suggests that Catimor may prefer or be more adapted to shade than Caturra (Muschler, 2001). This interaction is a genotype by environment interaction $(\mathrm{G} \times \mathrm{E})$ which is common in many plants.

\section{B. Bean colour}

The colour of green beans is a sign of freshness, moisture content, the level of defective beans and homogeneity (Mendonça et al., 2009). The green-bluish colour of washed Arabica beans is preferred relative to the browner beans of Robusta (Wintgens, 2012). Bean colour changes with different environments, for example, coffee grown at high altitude is often greenly-blue and if grown in soil lacking zinc, coffee beans may become light-grey in colour (Wintgens, 2012).

\subsubsection{Sensory evaluation}

Flavor, namely cup quality, is the primary standard in worldwide coffee trade (A Farah, et al., 2006). Having an even bean size and good appearance without defective beans does not always result in good coffee flavor (Wintgens, 2012). For this reason, it is important to judge the flavor quality in relation to the final utilization, such as roasted, liquid canned coffee, etc. Cup quality analysis aims to evaluate coffee flavor with a group of trained people in an objective and reproducible way to create a profile using established terminology, such as aroma, flavor, body and acidity, which has been established by the International Coffee Organization (ICO).

Coffee flavor is very sensitive to $\mathrm{G}$ and $\mathrm{E}$ changes. Acidity, for example, ranges dramatically in different washed Arabica, while Robusta has been described as low or no acidity at all with coarse liquor, harsh and cereal notes and thick body (Van der Vossen \& Walyaro, 1981). Ultimately, Arabica coffee is sold as blends with varying proportions of Robusta coffee, but Robusta coffees are seldom used alone (Wintgens, 2012). The same genotype planted in different environment may vary greatly in quality. For example, increasing positive attributes (appearance and preference) together with decreasing negative attributes (bitterness and astringency) was found in shade grown coffee (Muschler, 2001). This improvement may come from a balance of filled and uniform ripening coffee berries from the shade.

Another factor positively influencing quality is high altitude, which was shown to increase beverage quality 
of coffee (Avelino et al., 2005). Genotypes, such as Blue Mountain, SL-28, Pluma Hidalgo are famous worldwide due to their premium flavor, however, if grown in places other than their preferred environments do not always have a good flavor. Nevertheless, little is known about how G and E combinations generate high quality coffee.

\subsubsection{Chemical attributes}

The chemistry of coffee quality is highly complex with a wide range of compounds that change during fruit development. A few key components, such as caffeine, trigonelline, lipids, sucrose and chlorogenic acids (CGAs), are regarded as significant in influencing coffee quality. These components either stay stable and act as flavor attributes reaching the coffee brew or are degraded during roasting accounting for flavor precursors (Wintgens, 2012).

\section{A. Caffeine}

Caffeine is one of the most important bitterness attributes contributing to coffee quality. When caffeine is consumed moderately by humans, increased energy availability, alertness and concentration, decreased fatigue and boosted physical performance have been reported, however, too much caffeine may result in undesired effects such as cardiovascular disease, depression, and even addiction. Nowadays, caffeine is the world's most famous behaviorally active drug and is consumed primarily from coffee. Arabica coffee is popular for its lower caffeine content compared to Robusta, with $0.6-1.8 \%$ and $1.2-4.0 \%$ respectively.

In some coffee species there is no caffeine at all (Mazzafera \& Carvalho, 1991). Earlier research showed caffeine was increased when shade levels were increased from 0 to $45 \%$ in $C$. arabica beans and the same result was observed in a second year (Vaast et al., 2006). However, long-term influence of light on caffeine accumulation is not known. High altitude is another factor increasing caffeine content (Avelino et al., 2005). However, research to date has not investigated the influence on transcription to better understand the impact of high altitudes.

\section{B. Trigonelline}

Trigonelline is an aroma precursor that contributes to the desirable flavor products formed during coffee roasting, including pyrazine, furans, alkyl-pyridines and pyrroles (M. N. Clifford, 1985). Trigonelline decomposes rapidly depending on the roasting temperature. During the degradation process, a de-methylation process generates a water-soluble B vitamin, nicotinic acid, which is bio available in coffee beverages compared with other natural sources in bound forms (Trugo, 2003).

Unlike caffeine, Arabica contains higher levels of trigonelline than Robusta with $0.80-1.82 \%$ and $0.7-1.24 \%$, respectively (Bicho et al., 2013). Lower trigonelline was found in shade grown coffee beans (Vaast et al., 2006). Recent research, for example, revealed a decrease of trigonelline when increasing shade levels of $0-30 \%, 50 \%$ and then a rise at $70 \%$ and continued reduction in $80 \%$. Opposite to the impact of shade, high altitude increases trigonelline content during all stages of Robusta cherry development, however, in Arabica coffee, there is no difference detected.

\section{Chlorogenic acids}

Chlorogenic acids (CGAs) are a group of phenolic compounds that show multiple attributes. During roasting, a large percentage of the CGAs degrade to form caffeic acid, lactones and other phenol derivatives through Maillard and Strecker's reactions, which result in increased bitterness, astringency and aroma (Upadhyay \& Mohan Rao, 2013). CGAs are thermally unstable and in Arabica coffee the loss of CGAs after light roasting and after very dark roasting of beans corresponds to $60.9 \%$ and $96.5 \%$ respectively while in Robusta this loss corresponds to $59.7 \%$ to almost $98 \%$ respectively. Although most CGAs are lost by roasting, a sharp increase in total antioxidant activity was reported in the coffee beverage which suggested that the breakdown products of CGAs are antioxidants (Upadhyay \& Mohan Rao, 2013).

For the coffee plant itself, CGAs are significant plant metabolites that are associated with the protection of plant cells against stress, for example, oxidative stress, UV irradiation and pathogen infection (Matsuda et al., 2003; Niggeweg et al., 2004; Peterson et al., 2005). The total amount of CGAs is relatively lower in Arabica (4.08.4\%) compared to Robusta (7.0-14.4\%) (Bicho et al., 2013; C.-L.; Ky et al., 1997; Upadhyay and Mohan Rao, 2013). No significant relationship was found between CGA content and rainfall or evapo transpiration, and a minor negative correlation observed with solar irradiance.

Temperature is not to be ignored as a highly significant difference was detected (Joët et al., 2010). A warm climate provided by the low altitude coffee zone activated early accumulation of the major components and favoured subsequent remobilization of minor compounds. A delay of 5-CQA accumulation was found in a cooler climate and in 150-210 DAF of seed development 5-CQA accumulation was found to be positively correlated with temperature. Maximal CGA content was influenced by temperature because the CGA peaks at different stages in different climates and the variation in minor components remains until maturity (Joët et al., 2010). This suggests that transcriptional expression and co-regulation of genes of CGAs biosynthesis were influenced by bean developmental stage and temperature.

Temperature was not found to be positively correlated with final the CGA content. This is probably because all the coffee from 16 different locations (270-1032 m above sea level) was harvested at the same time. There are three reasons that might account for this outcome. The first is that high altitude with low temperature delays coffee 
seeds maturity resulting in a different maturity for each plot.

The second possible case is that CGA accumulation may be favoured by specific altitudes. Last but not least, this review was not designed especially for altitude and the environment was complicated by a combination of different climate factors. Shade was found to be another influencing factor as $45 \%$ shade (by slope inclination) slightly reduced CGA content in C. arabica Costa Rica 95 and increased shade from 0 to $80 \%$ (by shade trunk) caused a significant drop in CGA levels in C. arabica K7 (Vaast et al., 2006). Shade influences may arise from a different microclimate produced by shade or different genotype adaptations to shade.

\section{Sucrose}

Sucrose contributes more than $90 \%$ of the total low molecular carbohydrates in green coffee beans. Other low molecular sugars, for instance, glucose and fructose may also degrade or react with amino acids, but in green beans they represent only about $0.5 \%$ of the total. Sucrose content depends on the coffee genotype, with $7.4-11.1 \%$ in Arabica and 4.05-7.05\% in Robusta (Tran, Slade Lee et al., , 2016). Shade was found to reduce sucrose significantly by delaying the peak of SUS and SPS enzyme activity and resulting in higher SUS2 transcripts in coffee endosperm. The same SS and SPS activities were found in full sun and shade at 214 DAF, however, increases of these two enzyme activities until 260 DAF were reported in coffee grown under a shade treatment. Many reports have shown that plant adaption to low temperature involves an increase in soluble sugars, especially sucrose. Additionally, more work is required to determine how genotype, environment or the interaction of these two factors influences sucrose accumulation in coffee seeds during ripening.

\section{E. Lipids}

Coffee lipids contribute to the texture and mouth feel of the beverage as they carries flavors and fat-soluble vitamins. Kahweol and cafestol in the class of diterpene fatty acids attract much attention due to their paradoxical physiological effects that may increase serum cholesterol but potentially protect against carcinogenesis. However, tocopherols, another important group of lipids in green coffee beans that are present in small amounts, show antioxidant activities to humans. Roasting does not change most of the coffee lipids, however, they are difficult to retain in the final beverage.

In normal filtered preparations, for example, there are less than $0.2 \%$ lipids in the brew; for strongly roasted express, lipids accounts for 1-2\%. Arabica starts to store oil earlier and in higher concentrations than Robusta. Lipid content is also subject to environmental factors, such as shade, which results in higher levels (Vaast et al., 2006). High altitude is another factor in favor of fat accumulation (Avelino et al., 2005).

Moreover, a study working with short time extreme low temperature treatments found that five coffee genotypes responded differently to cold temperature; lipids increased in some coffee leaves to maintain cellular integrity but this was difficult for some genotypes which were observed to have lipid degradation together with damaged membranes. Shade and high altitude have the same influence on genes expression as low temperature remains to be determined. However, lipid metabolism is complex and needs further work to be fully understood. To date, no genes encoding malonyl-CoA ACP transacylase and ketoacyl-ACP synthase III have been found in the Coffea EST databases (Joët et al., 2009). Therefore, more work is needed to understand how these important components accumulate and what factors influences their accumulation.

\subsection{Current status of analysis of coffee quality and their limitations}

Although plenty of studies have been conducted on G, E and interaction influences on coffee quality, it is a highly complex process. A huge gap in knowledge remains. Firstly, coffee metabolism of key components is yet to be fully understood. The main metabolism pathways, including enzymes and their encoding genes need to be identified. In caffeine metabolism, for example, a highly purified 7-methylxanthosine synthase, encoding caffeine biosynthesis, native to coffee is yet to be isolated (Ogawa et al, 2001).

Secondly, transcriptional profiling using emerging next generation sequencing techniques is required to further understand coffee metabolism. Cost effective sequencing yielding more depth and coverage of sequencing coupled with improved data analyzing software will all support wide ranging experiments and gene expression analysis.

Thirdly, transcriptome studies are mainly analyzed with coffee plants instead of fruits, however, for coffee quality, fruit analysis is essential. Moreover, there is limited work combining metabolic analysis together with transcriptional analysis to define genotype, environment and GxE influences on coffee quality.

\subsection{Future prospects}

Regarding with quality stability Plants have a striking ability to evolve and adapt to different environment conditions with a phenotypic plasticity associated with physiology and metabolism changes. Genotype or environment influences can be captured by phenotypic or transcriptional profiling during coffee bean development. The release of the $C$. canephora genome recently and more transcriptional work published on $C$. engenioids and C. arabica have increased the potential for the study of $\mathrm{G}$ and $\mathrm{E}$ influences on Arabica or Robusta quality using transcriptome analysis. However, to take advantage of this opportunity, further studies will be required. Firstly, 
the main coffee metabolic pathways need to be fully understood during different development stages with key metabolites, enzymes and encoding genes identified.

Secondly, different genotypes or environment and their interaction impacts on coffee metabolism needs to be analyzed to determine how to use this knowledge to improve coffee quality. Furthermore, it is essential to understand how $\mathrm{G} \times \mathrm{E}$ affects coffee quality and how to utilize this knowledge to improve coffee quality. This can be used as a guide to RNA interference and transgenic studies to control key genes and modify the final accumulation of key quality components to improve coffee. However, one needs to make a balance between coffee quality and yields. For example, some environment factors, like shade, have been shown to positively improve coffee quality, but they were also observed to decrease coffee yield. A reduction in caffeine or CGAs may reduce bitterness in the brew, however, this might be a problem for the coffee plant if caffeine or CGAs levels are too low to allow the plants resist to pests and diseases.

\section{Conclusion}

Previous studies on coffee have shown that there is a differential response of quality when grown under different conditions and environments, and hence is an indication of the existence of genotype by environment $\mathrm{G} \times \mathrm{E}$ interaction. Coffee quality also varies in different genotypes. A huge gap in knowledge remains. Hence, further research is important with understanding of coffee metabolism, different genotypes or environment impacts on coffee metabolism and how $\mathrm{G} \times \mathrm{E}$ affects coffee quality and how to utilize this knowledge to improve coffee quality.

\section{References}

Avelino, B. Barboza, J.C. Araya, C. Fonseca, F. Davrieux and B. Guyot, 2005. Effects of slope exposure, altitude and yield on coffee quality in two altitude terroirs of Costa Rica, Orosi and Santa Maria de Dota Journal of the Science of Food and Agriculture, 85 (11), pp. 1869-1876.

Bicho, A.E. Leitão, J.C. Ramalho, N.B. de Alvarenga, F.C. Lidon, 2013. Impact of roasting time on the sensory profile of Arabica and Robusta coffee Ecology of Food and Nutrition, 52 (2), pp. 163-177.

Bunn $\mathrm{Ch}, 2015$. Modeling the climate change impacts on global coffee production. Dissertation for the completion of the academic degree Doctor rerum agriculturarum submitted to the faculty of Life Sciences at HumboldtUniversität zu Berlin.

F. Matsuda, K. Morino, M. Miyashita, H. and Miyagawa, 2003. Metabolic flux analysis of the phenylpropanoid pathway in wound-healing potato tuber tissue using stable isotope-labeled tracer and LC-MS spectroscopy Plant and Cell Physiology, 44 (5), pp. 510-517 http://dx.doi.org/10.1093/pcp/pcg063 Cross Ref.

Farah, M. Monteiro, V. Calado, A. Franca, L. Trugo, 2006. Correlation between cup quality and chemical attributes of Brazilian coffee Food Chemistry, 98 (2), pp. 373-380.

Gichuru EK, Agwanda CO, Combes MC, Mutitu EW, Ngugi ECK, Bertrand B, Lashermes P, 2008. Identification of molecular markers linked to a gene conferring resistance to coffee berry disease Colletotrichum kahawae in Coffea arabica. Plant Pathology, 57: 1117-1124.

International Coffee Organization (ICO), 2014. Fourth International World coffee Conference $112^{\text {th }}$ session from 7-14 march 14. London, United Kingdom. Available on: http://dev.ico.org/documents/cy2013-14/wccethiopia-presentation.pdf

Joët, A. Laffargue, J. Salmona, S. Doulbeau, F. Descroix, B. Bertrand and S. Dussert, 2009. Metabolic pathways in tropical dicotyledonous albuminous seeds: Coffea arabica as a case study New Phytologist, 182 (1), pp. $146-162$.

Joët, J. Salmona, A. Laffargue, F. Descroix, S, 2010. Dussert Use of the growing environment as a source of variation to identify the quantitative trait transcripts and modules of co-expressed genes that determine chlorogenic acid accumulation Plant, Cell \& Environment, 33 (7), pp. 1220-1233.

Ky C. L, Louarn J, Dussert S, Guyot B, Hamon S and Noirot M, 2001. Caffeine, trigonelline, chlorogenic acids and sucrose diversity in wild Coffea arabica L. and C. canephora P. accessions. Food Chemistry, 75: 223230.

M. Clifford, 1997. The nature of chlorogenic acids. Are they advantageous compounds in coffee? Paper presented at the COLLOQUE Scientifique International sur le Café, 17, Juillet, Nairobi (Kenya) (), pp. 20-25.

M.P. Maluf, C. C. d. Silva, M. d. P. A. d. Oliveira, A.G. Tavares, M.B. Silvarolla, O. Guerreiro and Filho, 2009. Altered expression of the caffeine synthase gene in a naturally caffeine-free mutant of Coffea arabica Genetics and Molecular Biology, 32 (4) (), pp. 802-810

Mendonça, A.S, and Franca, L.S and Oliveira, 2009. Physical characterization of non-defective and defective Arabica and Robusta coffees before and after roasting Journal of Food Engineering, 92 (4), pp. 474-479.

Muschler Shade improves coffee quality in a sub-optimal coffee-zone of Costa Rica Agroforestry Systems, 51 (2) (2001), pp. 131-139.

Ogawa, Y. Herai, N. Koizumi, T. Kusano and H. Sano, 2001.7-Methylxanthine methyl transferase of coffee plants 
Journal of Biological Chemistry, 276 (11), pp. 8213-8218

P. Mazzafera, A. Carvalho (1991). Breeding for low seed caffeine content of coffee (Coffea L.) by interspecific hybridization Euphytica, 59, pp. 55-60 http://dx.doi.org/10.1007/BF00025361View Record in Scopus

Silvarolla M.B., Mazzafera P. and Fazuoli L.C, 2004. Plant biochemistry: A naturally decaffeinated arabica coffee Nature, 429 (6994) 826.

Sunarharum, D.J, Williams, H.E and Smyth, 2014. Complexity of coffee flavor: A compositional and sensory perspective Food Research International, 62, pp. 315-325.

Tran, L. Slade Lee, A. Furtado, H. Smyth and R. Henry. Advances in genomics for the improvement of quality in Coffee Journal of the Science of Food and Agriculture, 96 (2016), pp. 3310-3312.

Trugo, P.M., 2003, Encyclopedia of food sciences and nutrition (2nd ed.), pp. 1498-1506.

Upadhyay, L.J and Mohan Rao, 2013. An outlook on chlorogenic acids - occurrence, chemistry, technology, and biological activities Critical Reviews in Food Science and Nutrition, 53 (9), pp. 968-984.

Vaast, B. Bertrand, J.J. Perriot, B. Guyot and M. Genard, 2006. Fruit thinning and shade improve bean characteristics and beverage quality of coffee (Coffea arabica L.) under optimal conditions Journal of the Science of Food and Agriculture, 86 (2), pp. 197-204.

Veddeler D, Olschewski R, Tscharntke T. \& Klein A.M, 2008. 'The contribution of non-managed social bees to coffee production: new economic insights based on farm-scale yield data'. Agro forestry Systems, 73: 109114.

Wamatu, J.N., Thomas, E. and Piepho, H.P., 2003. Responses of different arabica coffee (Coffea arabica L.) clones to varied environmental conditions. Euphytica, 129 (2), pp.175-182.

Wintgens, 2012. Coffee: Growing, processing, sustainable production. A guidebook for growers, processors, traders and researchers (2nd ed.) Wiley-VCH Verlag GmbH \& Co. KGaA, Weinheim, Germany.

Workafes W, Kassu K, 2000. Coffee production system in Ethiopia. Pp 90-106. In: Proceedings of work-shop on control of coffee berry disease in Ethiopia.13-15th. August 1999, Addis Ababa, Ethiopia. 